\title{
ГЕНЕТИКА ПОВЕДЕНИЯ
}

(C) С.А. Федотов,

Ю. В. Брагина, Н. Г. Беседина, Л. В. Даниленкова,

Е. А. Қамышева, Н. Г. Қамышев

Учреждение Российской академии наук Институт физиологии им. И.П. Павлова РАН, СанктПетербург

\&ля исследования молекулярных механизмов функционирования центральных генераторов моторного паттерна (ЦГМП) проведен скрининг коллекции Р-инсерционных мутантов дрозофилы на сильные отклонения в локомоции и песне ухаживания. У 21 мутанта был установлен сайт инсерции Р-элемента в геноме путем секвенирования фланговых последовательностей геномной ДНК. Биоинформационный анализ позволил определить группу геновкандидатов, возможных участников развития и функционирования ЦГМП. Для некоторых из выявленных генов возможность участия в ритмических моторных актах предполагается впервые (CG15630, Map205).

\% К Кючевые слова: дрозофила; моторные функции; локомоция; звукопродукция; песня ухаживания; Р-элемент; инсерционные мутации; скрининг; гены-кандидаты.

Поступила в редакцию 21.11.2011. Принята к публикации 20.01.2012

\section{ГЕНЕТИЧЕСКОЕ ИССЛЕДОВАНИЕ МОТОРНЫХ ФУНКЦИЙ DROSOPHILA MELANOGASTER}

\section{ВВЕДЕНИЕ}

Исследование нервных механизмов генерации ритмических движений является необходимым для лечения моторных дисфункций и восстановления утерянной двигательной активности в результате повреждений нервной системы (Gordon et al., 2006; Pearson, 2000). Несмотря на определенные успехи в изучении генераторов моторного паттерна на человеке и других млекопитающих (Goulding, Pfaff, 2005; Kiehn, Butt, 2003), исследования механизмов их работы на молекулярно-клеточном уровне в составе нейронных ансамблей продвигаются крайне медленно и находятся на начальной стадии.

Drosophila melanogaster обладает простой нервной системой, является модельным объектом, для которого разработаны уникальные по своим возможностям генетические методы. Поэтому ее использование может внести значительный вклад в исследование механизмов реализации моторных функций, в частности механизмов функционирования и управления работой центральных генераторов моторного паттерна (ЦГМП). Наличие сходства на молекулярном уровне в функционировании нервной системы позвоночных и насекомых (Fradkin et al., 2010; Marder, Bucher, 2001) позволяет переносить выявленные закономерности на более сложные объекты.

Исследование нервных структур и групп нейронов, чья активность связана с генерацией и регуляцией моторного паттерна локомоторных и других ритмических актов у дрозофилы, ведется достаточно давно (Clyne, Miesenböck., 2008; Martin et al., 1998; Schlichet, Hall, 1979; Strauss, 2002; Strauss, Heisenberg, 1990; Suster, Bate, 2002; Suster et al., 2003). Однако данные о молекулярных механизмах работы ЦГМП носят лишь фрагментарный характер (Banerjee et al., 2004). В такой ситуации часто является продуктивным использование скрининга мутантных линий с фенотипическими отклонениями от нормы (Moran, Kyriacou, 2009; Landis et al., 2003; Strauss, 2002; Venken, Bellen, 2007).

В нашей работе было проведено тестирование Р-инсерционных мутантов на наличие отклонений в локомоторном поведении и параметрах звукопродукции при сравнении с линией дикого типа Canton-S. По результатам тестирования была отобрана 21 линия, проявляющая нарушения и в обеих формах поведения. Проведенный молекулярногенетический анализ позволил определить список генов-кандидатов, продукты которых с высокой степенью вероятности участвуют в генерации ритмических движений. Для каждого из генов выполнен тщательный анализ литературных данных, что позволило выдвинуть предположения о возможной его роли в функционировании нервной системы. Наличие среди генов-кандидатов таких, которые кодируют вероятных участников ремоделирования микротрубочковой сети (Map205) и сигналинга, запускаемого тирозинкиназными рецепторами $(d r l, M E S R 4)$, 
позволяют предположить особое значение этих процессов в морфофункциональной организации генераторов моторного паттерна.

\section{МАТЕРИАЛЫ И МЕТОДЫ}

Тестирование моторной активности мутантных линий

В исследовании использовали созданную нами ранее коллекцию мутантных линий Drosophila melanogaster (более 1000 линий), полученных методом Р-инсерционного мутагенеза (Cooley et al., 1988). Қаждая линия несет одиночную случайную инсерцию Р-элемента - $P d L$-транспозона (рис. 1) (Landis et al., $2001)$ - в одной из аутосом. В качестве контроля служила линия дикого типа Canton-S (CS). Мух разводили и содержали на стандартной изюмно-дрожжевой среде при $25^{\circ} \mathrm{C}$ и 12 -часовом световом дне.

Регистрацию двигательной активности и запись песни ухаживания самца проводили у трехсуточных самцов с 9.00 до 18.00 при $\mathrm{t}=25^{\circ} \mathrm{C}$. Для измерения двигательной активности мух собирали под холодовым наркозом и содержали до опыта в группе по 30 особей. Для регистрации звукопродукции самцов собирали без наркоза и содержали до опыта индивидуально. Запись звуков осуществляли при ухаживании самца за оплодотворенной самкой линии CS.

Запись двигательной активности одновременно 20 особей осуществляли с помощью двух веб-камер и программы Drosophila tracks (автор - Н. Г. Камышев) с частотой 10 Гц с последующей обработкой данных анализирующим модулем программы (Қамышев, 2011).

Регистрацию звукопродукции проводили по ранее описанному методу (Попов и др., 2000). Программа DCSA (Drosophila courtship song analysis, автор Н. Г. Камышев) автоматически распознавала импульсный (ИП) и синусоидальный компоненты (СП) песни самца (рис. 2) и рассчитывала различные параметры песни ухаживания.

Статистический анализ параметров двигательной активности и звукопродукции проводили тестом рандомизации (Edgington, 1995).

Определение локализации и направленности PdL-транспозона в геноме

ДНК выделяли из 10 самок каждой мутантной линии. Для этого мух замораживали $\left(-20^{\circ} \mathrm{C}, 5\right.$ мин), го могенизировали в 200 мкл лизирующего буфера $(0,1 \mathrm{M}$ $\mathrm{NaCl}, 6.8 \%$ сахароза, 0,1M Трис-HCl, pH 8,5, 0,05M EDTA, 0,5 \% SDS, 0,5 \% DEPC), инкубировали лизат 30 мин при $65^{\circ} \mathrm{C}$, добавляли в лизат 300 мкл ацетата натрия ( $\mathrm{pH} 5,2)$, перемешивали, инкубировали на льду 30 мин и центрифугировали в течение 10 мин. при 12100 g. Полученный супернатант переносили в новый эппендорф и осаждали ДНК 96 \% -м этанолом с последующим центрифугированием. Осажденную ДНК промывали 75 \% -м этанолом, центрифугировали, подсушивали в термостате $\left(10\right.$ мин, $\left.37^{\circ} \mathrm{C}\right)$, растворяли в 0,01M Трис-HCl, $\mathrm{pH} 7,5$ и помещали на хранение при $-20^{\circ} \mathrm{C}$.

Для амплификации в инвертированной полимеразной цепной реакции (ПЦР) фланговой последовательности геномной ДНК, примыкающей к месту вставки PdL-транспозона, выделенную ДНК в количестве эквивалентном трем мухам расщепляли рестриктазой Taq1 при $65^{\circ} \mathrm{C}$ в течение 2 часов, а затем проводили лигирование фрагментов ДНК самих на себя Т4-лигазой при $4{ }^{\circ} \mathrm{C}$ на протяжении 16 часов. После рестрикции и самолигирования ДНК осаждали 96 \%-м этанолом с последующим центрифугированием. Полученный осадок подсушивали в термостате (10 мин, $\left.37{ }^{\circ} \mathrm{C}\right)$ и растворяли в бидистиллированной воде. ПЦР-амплификацию осуществляли с использованием праймеров HSP (CTGCAGATTGTTTAGCTTGTTC) и IRS (CGGGACCCACCTTATGTTAT) в термоциклере «Veriti» (Applied Biosystems) при следующих условиях: $95^{\circ} \mathrm{C}(3$ мин $) \times 1 ;\left[95^{\circ} \mathrm{C}(30 \mathrm{c}), 53^{\circ} \mathrm{C}(30 \mathrm{c}), 72^{\circ} \mathrm{C}\right.$ $(60 \mathrm{c})] \times 35 ; 72{ }^{\circ} \mathrm{C}(7$ мин $) \times 1$.

Секвенирование очищенного продукта ПЦР выполняли методом Сэнгера на оборудовании и реактивах Applied Biosystems. Сиквенсную реакцию проводили с использованием праймера HSP при следующих условиях: $95^{\circ} \mathrm{C}(60 \mathrm{c}) \times 1$; $\left[95^{\circ} \mathrm{C}(10 \mathrm{c})\right.$, $50{ }^{\circ} \mathrm{C}(5 \mathrm{c}), 60^{\circ} \mathrm{C}(4$ мин $\left.)\right] \times 25$. Обработка сиквенсов осуществлялась с помощью лицензионного программного обеспечения Applied Biosystems: Data Collection v3.0, Sequencing Analysis 5.3.1, SeqScape ${ }^{\circledR}$ Software. Полученную фланговую нуклеотидную последовательность сопоставляли с базой данных о геномной последовательности ДНК Drosophila melanogaster в программе Basic Local Alignment Search Tool (BLAST), предоставляемых в интернетpecypce National Center for Biotechnology Information ( NCBI).

\section{РЕЗУЛЬТАТЫ}

Отбор мутантных линий, проявляющих наиболее выраженные отклонения в параметрах двух типов моторной активности

По результатам поведенческого тестирования из коллекции Р-инсерционных мутантов дрозофилы отобрана 21 линия с ярко выраженными и воспроизводимыми отклонениями по параметрам локомоторной активности и песни ухаживания при сравнении с линией дикого типа CS (рис. 3). Особое внимание уделялось значениям межимпульсных интервалов и несущей частоте в импульсной песне самца, непосредственно характеризующих работу песенного генератора моторного паттерна (рис. 3). 


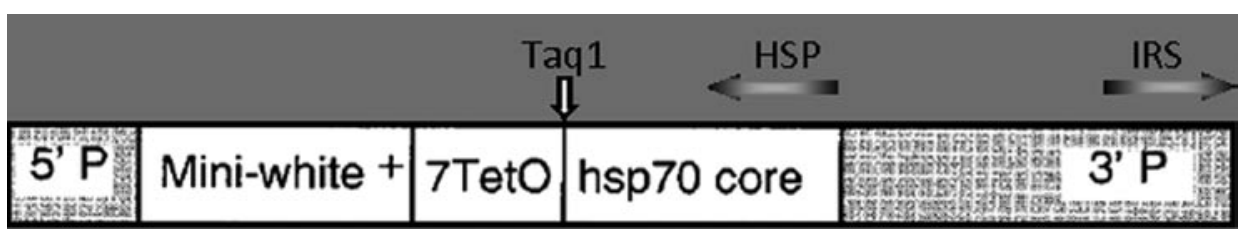

Puc. 1. Структура $P d L$-транспозона. 5'- и 3'- концевые последовательности Р-элемента необходимые для транспозиции обозначены заштрихованными прямоугольниками. Показаны сайт рестрикции Таq1 и праймеры, используемые в инвертированной ПЦР для амплификации фланговой последовательности геномной ДНК со стороны 3' -конца транспозона. Масштабы не соблюдены

\section{импульсный компонент: вибрация одного крыла}

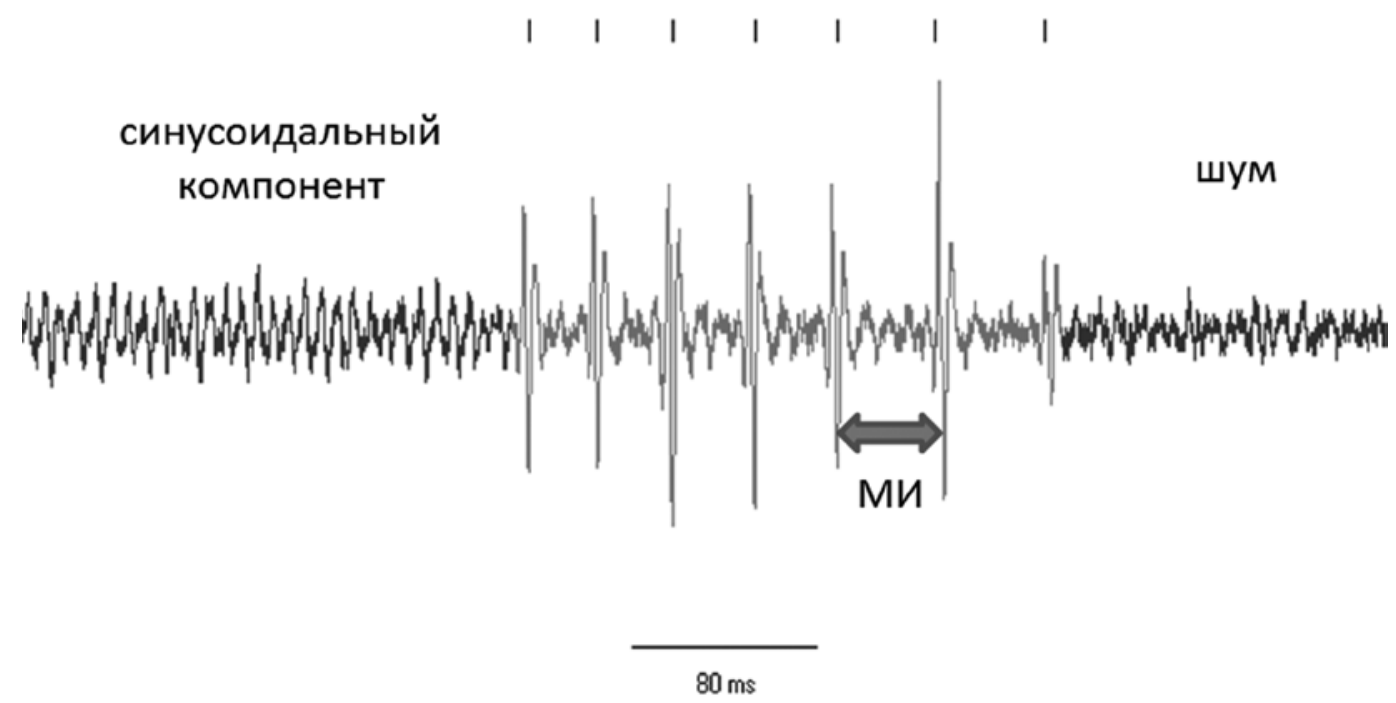

$\boldsymbol{P} \boldsymbol{u c . 2 .}$ Участок записи песни ухаживания самца дрозофилы. МИ - межимпульсный интервал

Ндентификация генов-кандидатов, определяющих параметры ритмических движений

Для выделенных по отклонениям в моторной активности мутантных линий определены локализация и направленность $P d L$-транспозона в геноме. Қаждая из 21 проанализированных линий имела уникальную точку инсерции $P d L$-транспозона. В 13 случаях вставка транспозона произошла в некодирующих участках в начале генов Cf2, Dpg-1, Ext2, lola, MESR4, Map205, Mef2, Sps2, Treh, wdp, CG5807, CG6746, CG15630; в двух случаях в кодирующей области генов jumu, CG8708; в одном случае в кластере транспозонов в перицентромерной области; в пяти остальных случаях в той или иной степени удаленности от 5'-конца генов drl, jing, mir-8, olf413, Hsrw (табл. 1).

На основе анализа существующих экспериментальных и биоинформационных данных по генам, затронутым вставкой $P d L$-транспозона (интернетресурсы FlyBase, NCBI), были определены или предположены функции продуктов этих генов и их роль в функционировании организма (табл. 1).

\section{ОБСУЖДЕНИЕ}

В группе предположительно затронутых мутациями генов-кандидатов, которые могут определять параметры моторной активности, половина кодирует факторы транскрипции и трансляции (7 генов) и рецепторные компоненты в мембранах клетки (4 гена). Другая половина представлена генами двух регуляторных РНК-молекул, двух гликозилтрансфераз, белка MAP205, связанного с микротрубочками, и различных ферментов клеточного метаболизма. Для генов lola и $d r l$ ранее была показана их вовлеченность в ритмическую активность у дрозофилы. Феминизация клеток, экспрессирующих lola, сопровождалась прекращением звукопродукции (Moran, Kyriacou, $2009)$, а для $d r l$ в исследовании с картированием локусов количественных признаков было показано, что он является существенным фактором, определяющим локомоторные параметры у мухи (Jordan et al., 2006).

Среди генов-кандидатов, кодирующих транскрипционные факторы (ТФ), можно четко выделить под- 
Таблища 1

Локализация $\boldsymbol{P} d \boldsymbol{L}$-транспозона в геноме у мутантных линий и гены-кандидаты, нарушение функций которых может отвечать за наблюдаемые отклонения моторного поведения

\begin{tabular}{|c|c|c|c|c|c|c|}
\hline Линия & $\begin{array}{c}\text { Положение } \\
\text { инсерции и направ- } \\
\text { ленность } P d L- \\
\text { транспозона }\end{array}$ & Ген-кандидат & Продукт гена & Функция гена & $\begin{array}{c}\text { Локализация } \\
\text { продукта гена } \\
\text { в клетке }\end{array}$ & $\begin{array}{c}\text { Гомолог } \\
\text { у человека }\end{array}$ \\
\hline 3724 & 2L- 4882790 - for & $C f 2$ & $\begin{array}{c}\text { Транскрипционный } \\
\text { фактор РНК- } \\
\text { полимеразы II }\end{array}$ & $\begin{array}{c}\text { Развитие } \\
\text { мышечных } \\
\text { органов } \\
\end{array}$ & Ядро & ZNF853 \\
\hline 663 & 2R-5842843-rev & Mef2 & $\begin{array}{c}\text { Предположительно } \\
\text { транскрипционный } \\
\text { фактор }\end{array}$ & $\begin{array}{c}\text { Развитие } \\
\text { скелетных, } \\
\text { гладких и } \\
\text { сердечных } \\
\text { мышц, } \\
\text { регуляция } \\
\text { активности } \\
\text { нейронов, } \\
\text { определяющих } \\
\text { суточные ритмы }\end{array}$ & Ядро & $M E F 2 A$ \\
\hline 5493 & 3R- 6182222 - for & jumu & $\begin{array}{c}\text { Предположительно } \\
\text { транскрипционный } \\
\text { фактор } \\
\end{array}$ & Нейрогенез & - & - \\
\hline $5282 b$ & 2R-6429208- for & lola & $\begin{array}{c}\text { Предположительно } \\
\text { транскрипционный } \\
\text { фактор } \\
\end{array}$ & $\begin{array}{c}\text { Регуляция } \\
\text { роста нервных } \\
\text { окончаний }\end{array}$ & Ядро & - \\
\hline 2169 & 2R-13435745-for & MESR4 & $\begin{array}{c}\text { Предположительно } \\
\text { транскрипционный } \\
\text { фактор } \\
\end{array}$ & $\begin{array}{l}\text { Клеточный } \\
\text { ответ на } \\
\text { гипоксию } \\
\end{array}$ & - & PELP1 \\
\hline 3494 & 2R-2389393-rev & jing & $\begin{array}{c}\text { Транскрипционный } \\
\text { репрессор }\end{array}$ & $\begin{array}{c}\text { Развитие } \\
\text { трахейной и } \\
\text { центральной } \\
\text { нервной } \\
\text { системы }\end{array}$ & Ядро & - \\
\hline $843 \mathrm{~K}$ & 2R-14059049- for & $\operatorname{Dg} p-1$ & $\begin{array}{c}\text { Предположительно } \\
\text { трансляционный } \\
\text { фактор элонгации }\end{array}$ & $\begin{array}{c}\text { Ответ на } \\
\text { стрессорные } \\
\text { воздействия } \\
\end{array}$ & - & GTPBPI \\
\hline $5567 \mathrm{a}$ & 3R-27894136-rev & Map205 & $\begin{array}{c}\text { Белок, } \\
\text { связывающий } \\
\text { микротрубочки }\end{array}$ & $\begin{array}{c}\text { Участие в ремо- } \\
\text { делировании } \\
\text { тубулиновой } \\
\text { сети при митозе }\end{array}$ & Цитоплазма & $M A P 4$ \\
\hline $3328 b$ & 3R-20639718-rev & CG5807 & $\begin{array}{c}\text { Предположительно } \\
\text { мембранный } \\
\text { рецептор } \\
\text { гидрофобных } \\
\text { агентов в составе } \\
\text { липокалина }\end{array}$ & $\begin{array}{c}\text { Развитие } \\
\text { половых клеток, } \\
\text { регуляция } \\
\text { секреции }\end{array}$ & - & $L M B R 1 L$ \\
\hline $3404 a$ & 2L-4793956- for & CG15630 & $\begin{array}{c}\text { Предположительно } \\
\text { рецепторный } \\
\text { компонент } \\
\text { плазматической } \\
\text { мембраны }\end{array}$ & - & - & PALLD \\
\hline 2248 & 2L-19190341-rev & $d r l$ & $\begin{array}{c}\text { Предположительно } \\
\text { тирозинкиназный } \\
\text { рецептор }\end{array}$ & $\begin{array}{c}\text { Направление } \\
\text { роста нервных } \\
\text { окончаний, } \\
\text { Wnt-сигналинг }\end{array}$ & - & $R Y K$ \\
\hline
\end{tabular}


Таблища 1 (окончание)

\begin{tabular}{|c|c|c|c|c|c|c|}
\hline Линия & $\begin{array}{c}\text { Положение } \\
\text { инсерции и направ- } \\
\text { ленность } P d L- \\
\text { транспозона } \\
\end{array}$ & Ген-кандидат & Продукт гена & Функция гена & $\begin{array}{c}\text { Локализация } \\
\text { продукта гена } \\
\text { в клетке }\end{array}$ & $\begin{array}{c}\text { Гомолог } \\
\text { у человека }\end{array}$ \\
\hline $\begin{array}{l}3979 a- \\
\text { s2 }\end{array}$ & 2R-18199553- rev & $w d p$ & $\begin{array}{c}\text { Предположительно } \\
\text { мембранный } \\
\text { рецептор }\end{array}$ & $\begin{array}{l}\text { Направление } \\
\text { роста аксонов }\end{array}$ & $\begin{array}{l}\text { Плазма- } \\
\text { тическая } \\
\text { мембрана }\end{array}$ & - \\
\hline $6225 \mathrm{a}$ & 2L-20116133-for & - & $\begin{array}{c}\text { Предположительно } \\
\text { пиРНК }\end{array}$ & - & - & - \\
\hline 3290 & 2R-12716378-rev & mir-8 & МикроРНК & $\begin{array}{c}\text { Регуляция } \\
\text { уровня } \\
\text { атрофина, } \\
\text { ингибирование } \\
\text { Notch- } \\
\text { индуцируемого } \\
\text { роста } \\
\end{array}$ & - & - \\
\hline $5433-\mathrm{t} 3$ & 3R-17122251-for & $H s r$ & $\begin{array}{c}\text { Предположительно } \\
\text { РНК, } \\
\text { связывающаяся } \\
\text { со сплайсосомой и } \\
\text { рибосомой }\end{array}$ & $\begin{array}{c}\text { Регуляция } \\
\text { созревания } \\
\text { пре-мРНК, } \\
\text { регуляция } \\
\text { белкового } \\
\text { синтеза } \\
\end{array}$ & $\begin{array}{l}\text { Ядро, цито- } \\
\text { плазма }\end{array}$ & - \\
\hline 4653 & 2R-4047132-for & CG8708 & $\begin{array}{c}\text { Бета-1,3- } \\
\text { галактозил- } \\
\text { трансфераза }\end{array}$ & $\begin{array}{c}\text { О-гликозилиро- } \\
\text { вание белков }\end{array}$ & - & B3GALT5 \\
\hline \multirow{2}{*}{$\begin{array}{l}6387 a- \\
\text { s2 }\end{array}$} & \multirow[t]{2}{*}{ 2R- 12036471 - for } & CG10731 & $\begin{array}{c}\text { Предположительно } \\
\text { регуляторный } \\
\text { компонент } \\
\text { митохондриальной } \\
\text { АТФ-синтазы }\end{array}$ & - & - & ATP5S \\
\hline & & Ext2 & $\begin{array}{c}\text { Предположительно } \\
\text { гликозил- } \\
\text { трансфераза }\end{array}$ & $\begin{array}{c}\text { Биосинтез } \\
\text { протеогликанов }\end{array}$ & \begin{tabular}{c|} 
Аппарат \\
Гольджи и \\
эндоплаз- \\
матическая сеть
\end{tabular} & EXT2 \\
\hline 5769 & 2L-10342643-for & Sps2 & $\begin{array}{c}\text { Предположительно } \\
\text { синтетаза } \\
\text { моноселено- } \\
\text { фосфата }\end{array}$ & $\begin{array}{c}\text { Синтез } \\
\text { селеноцистеина }\end{array}$ & Цитоплазма & SEPHS2 \\
\hline $5511-t 3$ & 3L- 22094200- for & olf4 13 & $\begin{array}{c}\text { Предположительно } \\
\text { дофамин-бета- } \\
\text { монооксигеназа }\end{array}$ & $\begin{array}{c}\text { Синтез } \\
\text { нейроэндокрин- } \\
\text { ных пептидов, } \\
\text { октопамина }\end{array}$ & - & MOXD1 \\
\hline 3389 & 2L-12002261-rev & CG6746 & $\begin{array}{c}\text { Предположительно } \\
\text { протеинтирозино- } \\
\text { вая фосфатаза }\end{array}$ & - & - & PTPLB \\
\hline $\begin{array}{l}4262 \mathrm{c}- \\
\mathrm{s} 2\end{array}$ & 2R-16964321-for & Treh & Трегалаза & $\begin{array}{l}\text { Расщепление } \\
\text { трегалозы }\end{array}$ & Мембрана & TREH \\
\hline \multicolumn{7}{|c|}{$\begin{array}{l}\text { В обозначении положения инсерции и направленности } P d L \text {-транспозона цифры } 2 \text { и } 3 \text { обозначают вторую или третью } \\
\text { хромосомы, буквы R и } L-\text { правое или левое плечо соответствующей хромосомы, многозначное число - номер нуклеотида } \\
\text { следующего за инсерцией, for и rev - направленность 3'-конца транспозона к окончанию нумерации нуклеотидов в хромосоме } \\
\text { или к ее началу }\end{array}$} \\
\hline
\end{tabular}




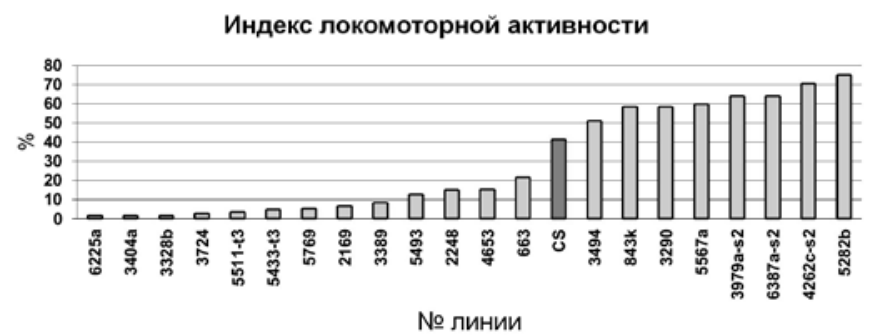

№ линии

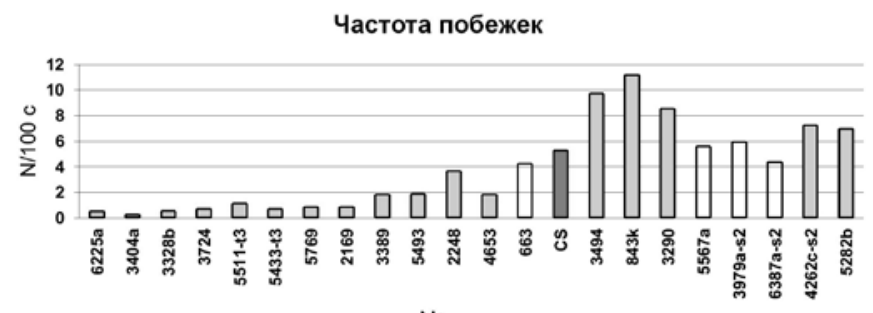

№ линии

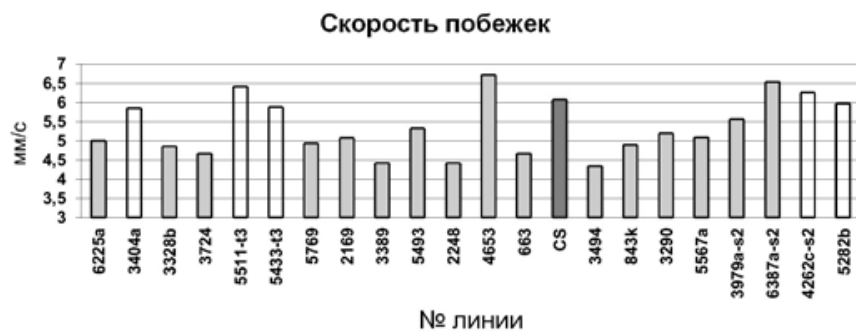

№ линии

Длительность побежек

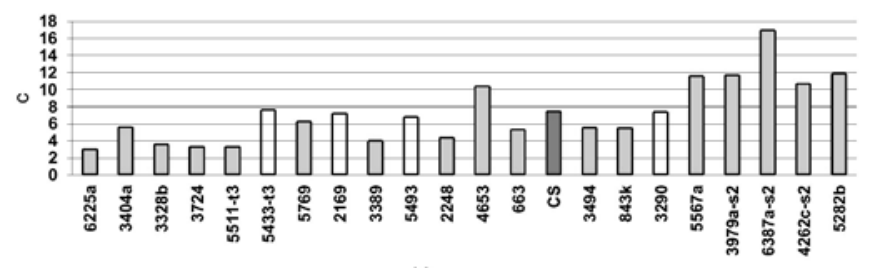

№ линии

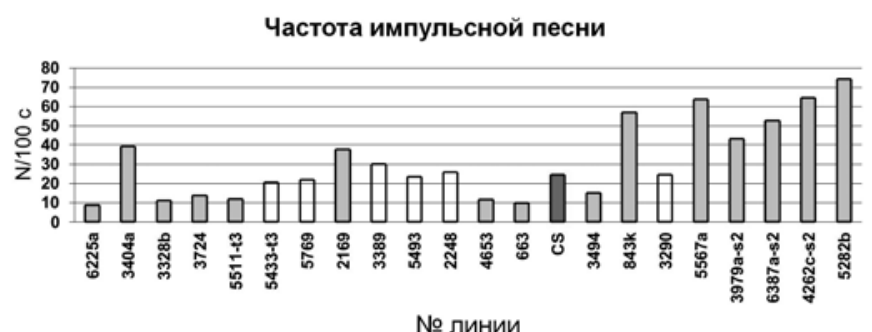

№ линии
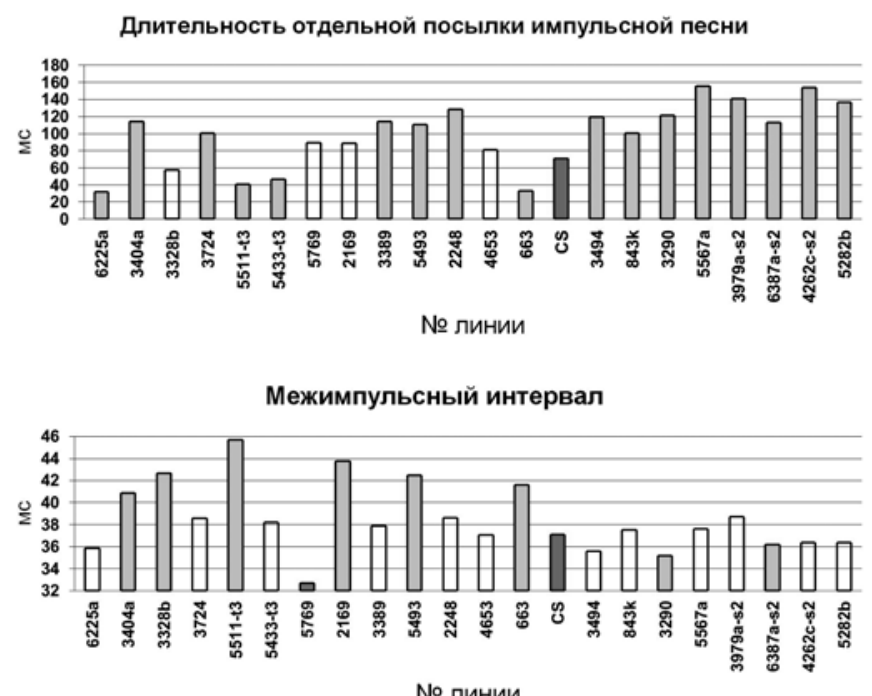

№ линии

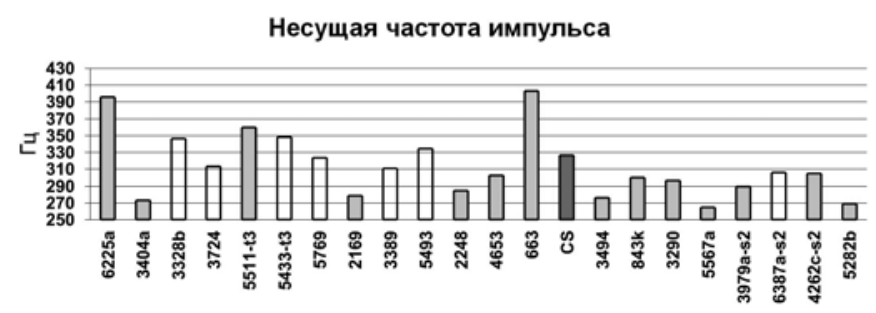

№ линии

$\boldsymbol{P} \boldsymbol{u c . 3 .}$ Отклонения в локомоторной активности и импульсной песне 21 мутантной линии в сравнении с линией дикого типа CS. На графиках представлены средние значения. Достоверно отличные значения выделены серым (тест рандомизации, 10000 итераций, $\mathrm{P}<0,05)$.

Индекс двигательной активности - время, занятое локомоцией, \%; частота побежек - количество инициаций побежек за 100 с; частота импульсной песни — количество инициаций посылок за 100 с; несущая частота импульса — 1/длительность самого выраженного цикла в импульсе.

группу из генов juma, lola, jing, определяющих развитие центральной нервной системы (ЦНС) с первых этапов ее формирования (Cheah et al., 2000; Crowner et al., 2002; Sonnenfeld et al., 2004). Экспрессия генов этих ТФ максимальна на эмбриональной стадии развития, а затем многократно снижается (Graveley et al., 2011). Моторные отклонения, вызываемые мутациями этих генов, существенно различаются и вероятнее всего вызваны множественными структурными дефектами на уровне органов и клеток ЦНС.

В данную подгруппу не включен ген MESR4 из-за ограниченности сведений о его роли в функционировании организма. Известно, что MESR4 является негативным регулятором EGFR/Ras/MAPK сигнального пути и его мисэкспрессия приводит к дефектам кутикулярных сенсорных органов и фоторецепторов (Abdelilah-Seyfried et al., 2000; Huang, Rubin, 2000; Pena-Rangel et al., 2002). Наблюдаемое изменение паттерна импульсной песни у мутантов MESR4 в сторону увеличения межимпульсного интервала и длительности импульса может быть связано с нарушениями в формировании рецепторов (Pearson, Wolf, 1987).

К другой подгруппе ТФ следует отнести продукты генов Mef2 и $C f 2$. Данные ТФ довольно подробно изучены в первую очередь с позиций их участия в 
развитии мышечных органов дрозофилы (Baker et al., 2005; Gajewski, Schulz, 2010). MEF2 и CF2 являются активаторами генов актина $A c t 57 B$, тропонина I TnI и тяжелой цепи миозина $M h c$ на эмбриональных и личиночных стадиях. При этом CF2 подвергается регуляции со стороны MEF2 (Tanaka et al., 2008). Недавно было показано, что MEF2 поддерживает суточные ритмы активности, регулируя экспрессию основных генов и влияя на взаимодействие нейронов, определяющих эти ритмы (Blanchard et al., 2010).

Таким образом, эффект мутаций генов Mef2 и $C f 2$ в виде депрессии моторной активности вероятнее всего связан с нарушениями в развитии мускулатуры животного. Однако сокращение межимпульсного интервала у мутантов по Mef2 на фоне данных об участии этого гена в работе нейронов мозга имаго указывают на возможные аномалии развития или работы элементов ЦНС. Мутация гена $C f 2$ с меньшей вероятностью связана с нарушениями ЦНС, учитывая сохранение паттерна импульсной песни.

Ген $D g p-1$ обнаруживает гомологию с консервативными доменами фактора элонгации 1 (Hunter et al., 2009). У млекопитающих наиболее близким гомологом является ген GTPBP1, прекращение функционирования которого не приводит к видимым фенотипическим отклонениям у мышей (Senju, et al., 2000). Для GTPBPI показана положительная регуляция интерфероном гамма, что может быть обобщено с данными об усилении экспрессии $D g p$-1 при оксидативном стрессе (Girardot et al., 2004; Gruenewald et al., 2009). Также экспрессия Dgp-1 и еще одного гена, выявленного в настоящем скрининге, Map205, увеличена почти в 2 раза у мутантов по гену park (на стадии куколки). Последний кодирует лигазу белка убиквитина, и прекращение функционирования его гомолога у человека приводит к развитию аутосомального рецессивного ювенильного паркинсонизма. Более того, у мутантов по гену park при прекращении функционирования генов Map205 и $\operatorname{Dgp}-1$, снижается выживаемость на 25 и 100 \% соответственно (Greene et al., 2005). Витальность мутантов с нефункционирующим GTPBP1 и усиление экспрессии Dgp-1 в условиях оксидативного стресса и на фоне мутации гена убиквитинлигазы park, позволяют предположить особое значение продуктов $\operatorname{Dgp}-1$ в противодействии нарушениям белкового метаболизма.

Мутация по гену Мар205, задействованному в ремоделировании тубулиновых волокон (Archambault et al., 2008), как и в случае с мутацией по гену Dgp-1 приводит к снижению скорости побежки и несущей частоты импульсной песни, но не затрагивает межимпульсный интервал. На С-конце Мар205 располагается консервативная последовательность, обнаруженная также в белке человека атаксин-2. Функция атаксина-2 не определена, но в его составе выявлен полиглутаминовый участок (CAG-повторы), экспансия повторов в котором связывается с развитием у человека спиномозжечковой атаксии второго типа (Lorenzetti, et al., 1997). В гене Мар205 также обнаруживается последовательность, кодирующая 5 глутаматных остатков примерно в том же положении, что и повтор из 20 глутаматных остатков в атаксине-2 у человека.

Принимая во внимание все вышесказанное, можно предположить, что инсерции в генах $D g p-1$ и Map205 приводят к нарушениям метаболизма белков в клетке, и как следствие этого, к сходным нейродегенеративным процессам, которые, однако, не затрагивают значения межимпульсного интервала в песне ухаживания.

Наряду с ТФ, другой подгруппой генов, определяющи параметры двигательной активности, являются рецепторные компоненты клеточных мембран, функционирование которых непосредственно связано с формированием и работой нейрональных ансамблей. В частности, хорошо изученный ген $d r l$ кодирует тирозинкиназный рецептор, лигандом которого является белок Wnt5, выделяемый аксонами нейронов (Wnt/Ryk сигналинг, Fradkin et al., 2010). Показано участие $d r l$ в направлении роста аксонов в брюшной нервной цепочке на стадии эмбрионального развития, развитии мозга имаго в процессе метаморфоза, в формировании нервно-мышечных синапсов личинок и других процессах развития (Liebl et al., 2008; Moreau-Fauvarque et al., 1998; Sakurai et al., 2009). Снижение локомоторной активности мутантов по этому гену вероятнее всего обусловлено структурными дефектами центрального комплекса мозга мухи (Strauss, 2002), а изменение характеристик импульсной песни может быть связано с нарушениями в восприятии и анализа обонятельных сигналов от самки, процессируемых в антеннальных долях и грибовидных телах (Yao et al., 2007). Следует отметить, что по результатам исследований многих авторов мутации генов, вовлеченных в тирозинкиназный сигналинг и его регуляцию (MESR3, aos, Gap1, lola, egh), приводят к различным моторным отклонениям и структурным аномалиям ЦНС дрозофилы (Boube et al., 1997; Moran, Kyriacou, 2009; Friedman, Perrimon, 2006; Huang, Rubin, 2000; Sawamoto et al., 1998).

Три остальных гена рецепторов практически не описаны в литературе. Для гена его сверхэкспрессия в мышцах личинки вызывает нарушения в иннервации отдельных мышц аксонами мотонейронов (mistargeting) (Kurusu et al., 2008). Эти нарушения иннервации могут быть причиной снижения несущей частоты импульса, наблюдаемой у данной мутантной линии. Фунцциональные харак- 
теристики консервативных доменов гена CG15630, представленных интернет-ресурсом InterPro (Hunter et al., 2009), и роль продуктов гомологичных ему генов у млекопитающих (Palld, Chien et al., 2002) позволяют предположить, что CG15630 кодирует белок, локализующийся на клеточной поверхности нейрональных клеток, где участвует в ремоделировании цитоскелета клетки, управляя формой клеток, их взаимодействием и миграцией (Boukhelifa et al., 2003; Luo et al., 2005; Otey et al., 2005). Описание консервативных доменов в InterPro (Hunter et al., 2009) и список выявленных взаимодействий в дигибридном анализе (Stark et al., 2011) по гену CG5807, указывают на то, что CG5807 может кодировать мембранный рецептор гидрофобных агентов (гормоны, токсины) в составе липокалина, посредством которого регулируются сигнальные каскады в клетке, связанные с развитием половых клеток и процессами секреции (Redl, 2000; Schulz et al., 2004).

К группе мембранных рецепторов близок по сво ей роли в определении нейрональных взаимодействий ген $E x t 2$, который кодирует гликозилтрансферазу, необходимуюдля биосинтезагепарансульфата (McCormick et al., 2000). Гепарансульфаты являются компонентами плазматических мембран клеток, где они могут функционировать как рецепторы и участвовать в клеточной адгезии и межклеточных взаимодействиях. Они также выступают компонентами синаптических пузырьков и других мембранных органелл. Установлено, что Ext2, влияя на синтез гепарансульфатпротеогликанов, играет ключевую роль в распределении морфогенов hedgehog, wingless и Decapentaplegic (Takei et al., $2004)$. Соответственно, влияние мутации Ext2 на параметры моторных функций могут быть связаны с нарушениями в развитии мухи, однако, учитывая преобладание экспрессии гена в ЦНС на стадиях личинки и имаго (Chintapalli et al., 2007; Graveley et al., 2011), можно предполагать особое значение продукта Ext2 в определении рецепторных свойств протеогликанов в составе цитоплазматической, везикулярной и других мембран клетки. Так как межимпульсный интервал изменен незначительно, то, вероятно, непосредственно работа ЦГМП не затронута, но существенно изменена регуляции его активности (увеличенные параметры локомоции и звукопродукции).

В заключение следует отметить наличие для большинства выявленных генов-кандидатов гомологов у млекопитающих и человека, что предполагает возможность переноса в дальнейшем результатов исследования молекулярных механизмов работы генераторов моторного паттерна на более сложноорганизованные нервные сети. Следует, однако, иметь в виду, что действие мутации в той или иной степе- ни распространяется на функционирование всех систем органов, и более определенно утверждать о вовлеченности гена в нервные механизмы генерации ритмической активности можно будет лишь по результатам изучения локальной экспрессии геновкандидатов в нервной системе и ее отделах.

\section{Благодарности:}

Работа поддержана грантом РФФИ № 08-0400997, подпрограммой «Генофонды и генетическое разнообразие» Президиума РАН и Федеральной целевой программой «Научные и научно-педагогические кадры инновационной России» на 2009-2013 годы.

\section{СПИСОК ЛИТЕРАТУРЫ}

1. Камышев Н. Г., 2011. Дрозофила как модельный объект для вскрытия молекулярных механизмов моторных и когнитивных дисфункций и поиска фармакологических способов их коррекции: количественный подход к оценке изменений локомоторного поведения // Международная научная конференция «Измерительные и информационные технологии в охране здоровья (МЕТРОМЕД2011)», Сборник научных трудов, Санкт-Петербург, С. $152-160$.

2. Попов A. B., Савватеева-Попова E. B., Камышев Н. Г., 2000. Особенности акустической коммуникации у плодовых мушек Drosophila melanogaster // Сенсорные системы. Т. 14. № 1. C. 60-74.

3. Abdelilah-Seyfried S., Chan Y. M., Zeng C. et al., 2000. A gain-of-function screen for genes that affect the development of the Drosophila adult external sensory organ // Genetics. Vol. 155. P. 733752 .

4. Archambault V., D'Avino P. P., Deery M. J. et al., 2008. Sequestration of Polo kinase to microtubules by phosphopriming-independent binding to Map205 is relieved by phosphorylation at a CDK site in mitosis // Genes Dev. Vol. 22. P. 2707-2720.

5. Baker P. W., Tanaka K. K., Klitgord N., Cripps R. M., 2005. Adult myogenesis in Drosophila melanogaster can proceed independently of myocyte enhancer factor-2 // Genetics. Vol. 170. P. 17471759 .

6. Banerjee S., Lee J., Venkatesh K. et al., 2004. Loss of flight and associated neuronal rhythmicity in inositol 1,4,5-trisphosphate receptor mutants of Drosophila // J. Neurosci. Vol. 24. P. 7869-7878.

7. Blanchard F. J., Collins B., Cyran S. A. et al., 2010. The transcription factor Mef2 is required for normal circadian behavior in Drosophila // J. Neurosci. Vol. 30. P. 5855-5865.

8. Boube M., Benassayag C., Seroude L., Cribbs D. L., 1997. Ras1-mediated modulation of Drosophila ho- 
meotic function in cell and segment identity // Genetics. Vol. 146. P. 619-628.

9. Boukhelifa M., Hwang S. J., Valtschanoff J. G. et al., 2003. A critical role for palladin in astrocyte morphology and response to injury // Mol. Cell Neurosci. Vol. 23. P. 661-668.

10. Cheah P. Y., Chia W., Yang X, 2000. Jumeaux, a novel Drosophila winged-helix family protein, is required for generating asymmetric sibling neuronal cell fates // Development. Vol. 127. P. 33253335.

11. Chien S., Reiter L.T., Bier E., Gribskov M., 2002. Homophila: human disease gene cognates in Drosophila // Nucleic Acids Research. Vol. 30. P. 149-151.

12. Chintapalli V.R., Wang J., Dow J. A. T., 2007. Using FlyAtlas to identify better Drosophila models of human disease // Nature Genetics. Vol. 39. P. 715-720.

13. Clyne J. D., Miesenböck G., 2008. Sex-specific control and tuning of the pattern generator for courtship song in Drosophila // Cell. Vol. 133. P. 354-363.

14. Cooley L., Kelley R., Spradling A., 1988. Insertional mutagenesis of the Drosophila genome with single P elements // Science. Vol. 4. P. 1121-1128.

15. Crowner D., Madden K., Goeke S., Giniger E., 2002. Lola regulates midline crossing of CNS axons in Drosophila // Development. Vol. 129. P. 1317-1325.

16. Edgington E. S., 1995. Randomization tests (3rd ed.). New York: Marcel Dekker.

17. Fradkin L. G., Dura J. M., Noordermeer J. N., 2010. Ryks: new partners for Wnts in the developing and regenerating nervous system // Trends in Neurosciences. Vol. 33. P. 84-92.

18. Friedman A., Perrimon N., 2006. A functional RNAi screen for regulators of receptor tyrosine kinase and ERK signaling // Nature. Vol. 444. P. 230-234.

19. Gajewski K. M., Schulz R. A., 2010. CF2 represses Actin $88 \mathrm{~F}$ gene expression and maintains filament balance during indirect flight muscle development in Drosophila // PLoS ONE. Vol. 5. P. e10713.

20. Girardot F., Monnier V., Tricoire H., 2004. Genome wide analysis of common and specific stress responses in adult Drosophila melanogaster // BMC Genomics. Vol. 5. P. 74.

21. Gordon I. T., Whelan P. J., 2006. Deciphering the organization and modulation of spinal locomotor central pattern generators // J. Exp. Biol. Vol. 209. P. 2007-2014.

22. Goulding M., Pfaff S. L., 2005. Development of circuits that generate simple rhythmic behaviors in vertebrates // Curr. Opin. Neurobiol. Vol. 15. P. 14-20.
23. Graveley B. R., Brooks A. N., Carlson J. W. et al., 2011. The developmental transcriptome of Drosophila melanogaster // Nature. Vol. 471. P. 473-479.

24. Greene J. C., Whitworth A. J., Andrews et al., 2005. Genetic and genomic studies of Drosophila parkin mutants implicate oxidative stress and innate immune responses in pathogenesis // Hum. Mol. Genet. Vol. 14. P. 799-811.

25. Gruenewald C., Botella J. A., Bayersdorfer F. et al., 2009. Hyperoxia-induced neurodegeneration as a tool to identify neuroprotective genes in Drosophila melanogaster // Free Radical Biol. Med. Vol. 46. P. $1668-1676$.

26. Huang A. M., Rubin G. M., 2000. A misexpression screen identifies genes that can modulate RAS1 pathway signaling in Drosophila melanogaster // Genetics. Vol. 156. P. 1219-1230.

27. Hunter S., Apweiler R., Attwood T. K. et al., 2009. InterPro: the integrative protein signature database // Nucleic Acids Res. Vol. 37. P. D211-D215

28. Jordan K. W., Morgan T. J., Mackay T. F., 2006. Quantitative trait loci for locomotor behavior in Drosophila melanogaster // Genetics. Vol. 174. P. 271-284.

29. Kiehn O., Butt S. J. B., 2003. Physiological, anatomical and genetic identification of CPG neurons in the developing mammalian spinal cord // Progress in Neurobiology. Vol. 70. P. 347-361.

30. Kurusu M., Cording A., Taniguchi M. et al., 2008. A screen of cell-surface molecules identifies leucinerich repeat proteins as key mediators of synaptic target selection // Neuron. Vol. 59. P. 972-985.

31. Landis G. N., Bhole D., Lu L., Tower J., 2001. Highfrequency generation of conditional mutations affecting Drosophila melanogaster development and life span // Genetics. Vol. 158. P. 1167-1176.

32. Landis G. N., Bhole D., Tower J., 2003. A search for doxycycline-dependent mutations that increase Drosophila melanogaster life span identifies the VhaSFD, Sugar baby, filamin, fwd and Cetl genes // Genome Biol. Vol. 4. P. R8.

33. Liebl F. L., Wu Y., Featherstone D. E. et al., 2008. Derailed regulates development of the Drosophila neuromuscular junction // Dev. Neurobiol. Vol. 68. P. 152-165.

34. Lorenzetti D., Bohlega S., Zoghbi H. Y., 1997. The expansion of the CAG repeat in ataxin-2 is a frequent cause of autosomal dominant spinocerebellar ataxia // Neurology. Vol. 49. P. 1009-1013.

35. Luo H., Liu X., Wang F. et al., 2005. Disruption of palladin results in neural tube closure defects in mice // Mol. Cell. Neurosci. Vol. 29. P. 507-515.

36. Marder E., Bucher D., 2001. Central pattern generators and the control of rhythmic movements // Curr. Biol. Vol. 11. P. R986-R996. 
37. Martin J. R., Ernst R., Heisenberg M., 1998. Mushroom bodies suppress locomotor activity in Drosophila melanogaster // Learn. Mem. Vol. 5. P. 179191.

38. McCormick C., Duncan G., Goutsos K. T., Tufaro F., 2000. The putative tumor suppressors EXT1 and EXT2 form a stable complex that accumulates in the Golgi apparatus and catalyzes the synthesis of heparan sulfate // Proc. Natl. Acad. Sci. USA. Vol. 97. P. 668-673.

39. Moran C. N., Kyriacou C. P., 2009. Functional neurogenomics of the courtship song of male Drosophila melanogaster // Cortex. Vol. 45. P. 18-34.

40. Moreau-Fauvarque C., Taillebourg E., Boissoneau $E$. et al., 1998. The receptor tyrosine kinase gene linotte is required for neuronal pathway selection in the Drosophila mushroom bodies // Mech. Dev. Vol. 78. P. 47-61.

41. Otey C. A., Rachlin A., Moza M. et al., 2005. The palladin/myotilin/myopalladin family of actinassociated scaffolds // Int. Rev. Cytol. Vol. 246. P. 31-58.

42. Pearson K. G., 2000. Neural adaptation in the generation of rhythmic behavior // Annu. Rev. Physiol. Vol. 62. P. 723-753.

43. Pearson K. C., Wolf H., 1987. Comparison of motor patterns in the intact and deafferented flight system of the locust. I. Electromyographic analysis // J. Comp. Physiol. A. Vol. 160. P. 259-268.

44. Pena-Rangel M. T., Rodriguez I., Riesgo-Escovar J. R., 2002. A misexpression study examining dorsal thorax formation in Drosophila melanogaster // Genetics. Vol. 160. P. 1035-1050.

45. Redl B., 2000. Human tear lipocalin // Biochim. Biophys. Acta. Vol. 1482. P. 241-248.

46. Sakurai M., Aoki T., Yoshikawa S. et al., 2009. Differentially expressed $\mathrm{Drl}$ and $\mathrm{Drl}-2$ play opposing roles in Wnt5 signaling during Drosophila olfactory system development // J. Neurosci. Vol. 29. P. 4972-4980.

47. Sawamoto K., Taguchi A., Hirota Y. et al., 1998. Argos induces programmed cell death in the developing Drosophila eye by inhibition of the Ras pathway // Cell Death Differ. Vol. 5. P. 262-270.

48. Schlichet F., Hall J. C, 1979. Neural topography of courtship song in sex mosaics of Drosophila melanogaster // J. Comp. Physiol. A. Vol. 129. P. 85-95.

49. Schulz C., Kiger A. A., Tazuke S. I. et al., 2004. A misexpression screen reveals effects of bag-ofmarbles and TGF beta class signaling on the Drosophila male germ-line stem cell lineage // Genetics. Vol. 167. P. 707-723.

50. Senju S., Iyama K., Kudo H. et al., 2000. Immunocytochemical analyses and targeted gene disruption of GTPBP1 // Mol. Cell. Biol. Vol. 20. P. 6195-6200.
51. Sonnenfeld M.J., Barazesh N., Sedaghat Y., Fan C., 2004. The jing and rasl pathways are functionally related during CNS midline and tracheal development // Mech. Dev. Vol. 121. P. 1531-1547.

52. Stark C., Breitkreutz B.J., Chatr-Aryamontri A. et al., 2011. The BioGRID interaction database: 2011 update // Nucleic Acids Res. Vol. 39. P. D698-D704.

53. Strauss R., 2002. The central complex and the genetic dissection of locomotor behavior // Curr. Opin. Neurobiol. Vol. 12. P. 633-638.

54. Strauss R., Heisenberg M., 1990. Coordination of legs during straight walking and turning in Drosophila melanogaster // J. Comp. Physiol. A. Vol. 167. P. 403-412.

55. Suster M. L., Bate M., 2002. Embryonic assembly of a central pattern generator without sensory input // Nature. Vol. 416. P. 174-178.

56. Suster M. L., Martin J. R., Sung C., Robinow S., 2003. Targeted expression of tetanus toxin reveals sets of neurons involved in larval locomotion in Drosophila // J. Neurobiol. Vol. 55. P. 233246.

57. Takei Y., Ozawa Y., Sato M. et al., 2004. Three Drosophila EXT genes shape morphogen gradients through synthesis of heparan sulfate proteoglycans // Development. Vol. 131. P. 73-82.

58. Tanaka K. K., Bryantsev A. L., Cripps R. M., 2008. Myocyte enhancer factor 2 and chorion factor 2 collaborate in activation of the myogenic program in Drosophila // Mol. Cell. Biol. Vol. 28. P. 1616-1629.

59. Venken K. J., Bellen H. J., 2007. Transgenesis upgrades for Drosophila melanogaster // Development. Vol. 134. P. 3571-3584.

60. Yao Y., Wu Y., Yin C. et al., 2007. Antagonistic roles of Wnt5 and the Drl receptor in patterning the Drosophila antennal lobe // Nat. Neurosci. Vol. 10. P. 1423-1432.

\section{GENETIC STUDY OF MOTOR FUNCTIONS IN DROSOPHILA MELANOGASTER}

Fedotov S. A., Bragina J. V., Besedina N. G., Danilenkova L. V., Kamysheva E. A., Kamyshev N. G.

\& SUMMARY: To investigate molecular mechanisms of central pattern generators (CPG s) functioning, we carried out a screening of collection of Drosophila P-insertional mutants for strong deviations in locomotion and courtship song. In 21 mutants, the site of the P-insertion was localized by sequencing of the fragments of genomic DNA flanking the P-element. Bioinformational analysis revealed a list of candidate genes, potential players in development and functioning of CPG s. Possible involvement of certain identified genes in rhythmic motor activity is suggested for the first time (CG15630, Map205). 
83

KEY WORDS: Drosophila; motor functions; locomotion; sound production; courtship song; P element; insertional mutations; screening; candidate genes.

\section{母н Информация об авторах}

Федотов Сергей Александрович — аспирант, младший научный сотрудник, Учреждение Российской академии наук Институт физиологии им. И. П. Павлова РАН. Лаборатория физиологии высшей нервной деятельности. Санкт-Петербург, 199034, наб. Макарова, д. 6.

Брагина Юлия Валерьевна - старший научный сотрудник, кандидат биологических наук, Учреждение Российской академии наук Институт физиологии им. И. П. Павлова РАН. Лаборатория сравнительной генетики поведения. Санкт-Петербург, 199034, наб. Макарова, д. 6.

Беседина Наталья Геннадьевна - старший научный сотрудник, кандидат биологических наук, Учреждение Российской академии наук Институт физиологии им. И. П. Павлова РАН. Лаборатория сравнительной генетики поведения. Санкт-Петербург, 199034, наб. Макарова, д. 6.

Даниленкова Лариса Владимировна - младший научный сотрудник, кандидат биологических наук, Учреждение Российской академии наук Институт физиологии им. И. П. Павлова РАН. Лаборатория сравнительной генетики поведения. Санкт-Петербург, 199034, наб. Макарова, д. 6.

Камышева Елена Аркадьевна - младший научный сотрудник, без ученой степени, Учреждение Российской академии наук Институт физиологии им. И. П. Павлова РАН. Лаборатория сравнительной генетики поведения. Санкт-Петербург, 199034, наб. Макарова, д. 6.

Камышев Николай Григорьевич - руководитель лаборатории, доктор биологических наук, старший научный сотрудник, Учреждение Российской академии наук Институт физиологии им. И. П. Павлова РАН. Лаборатория сравнительной генетики поведения. Санкт-Петербург, 199034, наб. Макарова, д. 6. E-mail: nkam@pavlov.infran.ru
Fedotov Sergey Aleksandrovich — Phd student, junior researcher. Pavlov Institute of Physiology, Russian Academy of Sciences. Laboratory of physiology of the higher nervous activity. SaintPetersburg, 199034, Makarova emb., 6.

Bragina Julia Valerjevna - senior staff scientist, candidate of biological science. Pavlov Institute of Physiology, Russian Academy of Sciences. Laboratory of comparative genetics of behavior. Saint-Petersburg, 199034, Makarova emb., 6.

Besedina Natalia Gennadievna - senior staff scientist, candidate of biological science. Pavlov Institute of Physiology, Russian Academy of Sciences. Laboratory of comparative genetics of behavior. SaintPetersburg, 199034, Makarova emb., 6.

Danilenkova Larisa Vladimirovna - junior researcher, candidate of biological science. Pavlov Institute of Physiology, Russian Academy of Sciences. Laboratory of comparative genetics of behavior. SaintPetersburg, 199034, Makarova emb., 6.

Kamysheva Elena Arkadjevna - junior researcher. Pavlov Institute of Physiology, Russian Academy of Sciences. Laboratory of comparative genetics of behavior. Saint-Petersburg, 199034, Makarova emb., 6.

Kamyshev Nikolai Grigorjevich - Head of laboratory, doctor of biological science, senior staff scientist. Pavlov Institute of Physiology, Russian Academy of Sciences. Laboratory of comparative genetics of behavior. Saint-Petersburg, 199034, Makarova emb., 6. E-mail: nkam@pavlov.infran.ru 